\title{
Enunciación
}

\section{La imagen en las artes plásticas y visuales. Nuevos modos de comunicación en la escuela ${ }^{1}$}

\author{
The image in the visual arts. New ways of communications at school \\ Flor Ángela Gutiérrez Castro²
}

Para citar este artículo: Gutiérrez, F. A. (2015). La imagen en las artes plásticas y visuales. Nuevos modos de comunicación en la escuela. Enunciación, 20(2), pp. 207-221.

Recibido: 27-septiembre-2015 / Aprobado: 25-noviembre-2015

"La imagen" no es un artefacto puramente visual, puramente icónico, ni un fenómeno físiCo, sino que es la práctica social material que produce una cierta imagen y que la inscribe en un marco social particular. La pintura, el cine, la fotografía, la televisión, y todos los otros géneros que podamos considerar "visuales", siempre involucran a otros sentidos, pero sobre todo a creadores y receptores, productores y consumidores, y ponen en juego una serie de saberes y disposiciones que exceden en mucho a la imagen en cuestión.

Dussel (2005, p. 161).

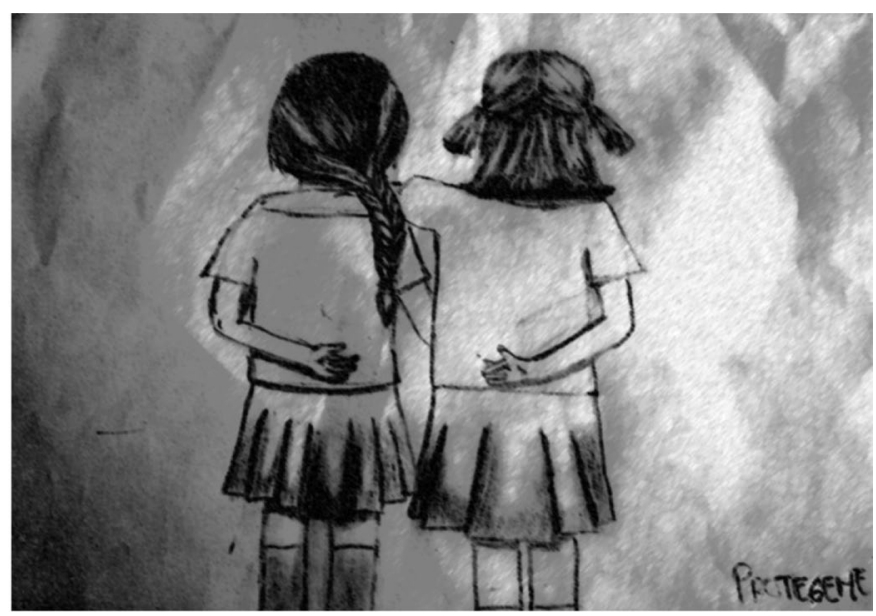

Figura 1. Serie. Mi mundo y yo.

Fuente: Karen Castañeda (13 años). Taller de dibujo estudiantes escuela pública básica secundaria dirigido por Flor Ángela Gutiérrez. Bogotá, Colombia. 2015.

1 Este artículo de reflexión corresponde al estudio realizado sobre uno de los referentes teóricos del proyecto de tesis doctoral "La imagen en la cultura visual y sus implicaciones en los procesos de subjetividad de los jóvenes. Cuestiones para pensar y transformar las prácticas pedagógicas en las artes visuales", que se adelanta en el Doctorado Interinstitucional en Educación de la Universidad Distrital Francisco José de Caldas, Bogotá (Colombia), bajo la tutela de la doctora Sandra Soler Castillo.

2 Magíster en Docencia de la Universidad de La Salle. Estudiante del Doctorado Interinstitucional en Educación, sede Universidad Distrital Francisco José de Caldas. Docente del Área de Educación Artística y Cultural en escuela pública de Bogotá (Colombia). Correo electrónico: anguca_80@hotmail.com 


\section{Resumen}

Este artículo de reflexión tiene como objetivo describir otras posibilidades y reconocimientos al uso de la imagen visual en los nuevos modos de comunicación en la escuela, mediante el desarrollo de algunas estrategias de acción referidas a la contemplación y la producción de la imagen: primero, sortear la tendencia a la transmisión de imágenes como reflejo transparente de realidades sugeridas; segundo, ir más allá de la interpretación de las imágenes en términos de lo negativo/positivo, y tercero, considerar en la escuela la importancia de las artes visuales en la construcción del sujeto. A partir de esta reflexión se desarrollan algunas claves conceptuales de la imagen como componente de la subjetividad desde rasgos distintivos que la revelan más desde su contenido que desde su definición. El artículo concluye con un esbozo sobre la necesidad de construir nuevas prácticas pedagógicas, en las que más allá de favorecer el cumplimento de programas académicos instaurados se construyan otras condiciones para entender la imagen como acontecimiento comprensible mediante la relación cultural visual artes visuales.

Palabras clave: imagen, cultura visual, artes visuales, escuela y comunicación.

\section{A MANERA DE INTRODUCCIÓN}

En la configuración de las prácticas escolares en las artes plásticas y visuales es indispensable reconocer una serie de posibilidades del uso de la imagen visual en los nuevos modos de comunicación en la escuela, mediante el desarrollo de algunas estrategias de acción que le apuesten a la lucha por asignarles un valor más significativo a los procesos de subjetividad. Esta apreciación se contempla dentro de la relación que se ha venido tejiendo en las artes plásticas y visuales entre la cultura visual y la escuela, es decir, de un distanciamiento mutuo a una correspondencia pedagógica con función estética favorecedora de las formas de ser y estar en el mundo de los sujetos jóvenes.

\begin{abstract}
This is a reflexive article which explains other possibilities and acknowledgements to the use of the visual image in the new ways of communication used at school, through the development of some strategies of action related to the contemplation and the image production: first, negotiate the tendency to the images transmission as a transparent reflecting suggested reality; secondly, to go beyond the interpretation of the images in terms of the negative or positive; and finally, to consider the importance of visual arts in school in the construction of the individual. Based on this reflection some essential concepts are developed about the image as a component of subjectivity since distinctive features that reveal more about its content rather than its definition. The article concludes by outlining the need to build new pedagogical practices, in which beyond promoting the compliance of established academic programs other conditions are built to understand the image as a comprehensible occurrence through the cultural visual-visual arts relationship.
\end{abstract}

Keywords: picture, visual culture, visual arts, school and communication.

Estos desarrollos inmersos en los procesos de enseñanza/aprendizaje no tienen otro interés que la formación integral del sujeto en medio del desarroIlo cultural. Parafraseando a Mora y Osses (2012, p. 324), es una pretensión que no busca dividir el pensamiento del sentimiento, sino más bien otorgarle un nuevo valor al sentir como función que potencializa el desarrollo humano, e integrar ambos aspectos para estar en mayor capacidad de comprender el mundo y a sí mismo. En esta medida, las artes visuales en la escuela han evolucionado y han cobrado protagonismo más recientemente a causa del uso de la tecnología en la expresión con diversos medios como la fotografía, el cine, el video arte, y también desde distintas herramientas artísticas en medios digitales y otros formatos de transmisión de imágenes como libros, revistas, televisión, bellas artes o Web. 
En este escenario constituido tanto desde la indagación investigativa que ha propuesto el análisis de diferentes prácticas pedagógicas en las artes plásticas y visuales, como desde la propia experiencia de trabajo con la imagen en la escuela, se despliega la hipótesis planteada a partir del desarrollo de algunas estrategias de acción en lo concerniente al uso, la producción y la reproducción de la imagen en las artes plásticas y visuales:

1. Sortear la tendencia a la transmisión de imágenes como reflejo transparente de realidades sugeridas.

2. Ir más allá de la interpretación de las imágenes en términos de lo negativo/positivo.

3. Considerar en la escuela la importancia de las artes visuales en la construcción de sujeto.

Lo anterior para, desde una esfera de significados, construir el concepto de imagen como componente de la subjetividad desde dos rasgos distintivos que la revelan más desde su contenido que desde su definición: en su actividad comunicativa como elemento que materializa la experiencia humana en el espacio/tiempo, y en su "expresión como lenguaje joven" (Bachelard, 2000, p. 11).

Esta perspectiva, tejida en medio de las condiciones contemporáneas, permite redefinir en este texto el contenido de la imagen, no en los límites de los tipos de las formas visuales que representa un aspecto concreto o abstracto, sino como una práctica social tangible en su temporalidad y uso (práctica de acción inscrita en un contexto propio). Esta es una clarificación importante para entender el recorrido que permitió llegar a la comprensión de la imagen como componente de la subjetividad, es decir, un lenguaje narrativo, un objeto de conocimiento que restablece una oportunidad de poner un mundo ante la mirada, dar las posibilidades de significarlo y otorgarle sentido.

Por último, mediante la idea de la difusión de la cultura visual en relación con las formas artísticas tradicionales, las artes plásticas y visuales, las artes escénicas, las artes musicales y el arte danzario, como disciplinas que constituyen actualmente el campo de la educación artística en la escuela colombiana, el texto deja claro que, de acuerdo con Freedman (2006), "una educación artística insuficiente es preocupante no solo [...] porque el arte visual sea algo relevante en cuanto forma de expresión humana, sino porque gran parte de la cultura contemporánea se ha hecho visual" (p. 20). Esto nos ha permitido "ver cosas que eran inimaginables, cruzar las fronteras de la forma tradicional en las bellas artes, hacia los medios de comunicación, hacia la visualización científica" (p. 42). Tras este transitar por la universalización de las imágenes, el texto concluye con el reconocimiento de nuevas condiciones en las prácticas pedagógicas que le apuesten a la humanización de la escuela y respondan al impacto de las formas visuales más allá de los límites tradicionales del proceso enseñanza/aprendizaje.

\section{METODOLOGÍA}

La cultura visual en las artes visuales como parte de la construcción conceptual del proyecto de tesis doctoral "La imagen en la cultura visual y sus implicaciones en los procesos de subjetividad de los jóvenes. Cuestiones para pensar y transformar las prácticas pedagógicas en las artes visuales", y como objeto de estudio de esta reflexión se aborda a partir de una perspectiva educacional y dialógica entre: a) presupuestos epistemológicos de distintos autores que han venido construyendo el campo de las artes visuales (Mirzoeff, 2003; Freedman, 2006; Mejía, 2011; Olaya, 2009; Hernández, 2010); b) investigaciones en educación artística desde una dimensión pedagógica (Marín, 2011; Giráldez y Pimentel, 2011; Mora y Osses, 2012), c) uso de conocimientos desde la propia experiencia como docente de artes plásticas y visuales de escuela pública de Bogotá. Estos elementos implican tanto la puesta en práctica de conocimientos científicos como criterios de conocimiento empírico.

Alrededor del tópico sobre el cual se reflexiona, en este artículo se explican otras posibilidades 
y reconocimientos al uso de la imagen visual en los nuevos modos de comunicación en la escuela mediante tres consideraciones preliminares. Argumentos que, al expresarse en un orden lógico y adoptando el esquema de subtítulos, permiten desarrollar algunas claves conceptuales de la imagen como componente de la subjetividad desde dos rasgos distintivos que la revelan más desde su contenido que desde su definición. A partir de esta reflexión unificada, se logra esbozar una primera postura epistemológica que le apueste a prácticas pedagógicas en la educación artística, encausadas a la relación cultural visual/artes visuales como aspectos imprescindibles en la configuración del joven como sujeto.

\section{LA CULTURA VISUAL Y SU PERSPECTIVA EDUCACIONAL}

Desde hace aproximadamente tres décadas la cultura visual ha pasado por una serie de transformaciones y percepciones que, al mismo tiempo, se han visto manifestadas de manera significativa en los procesos comunicativos de los jóvenes en la escuela. La globalización y sus fenómenos, comprendida como "la intensificación de las relaciones económicas, políticas, sociales y culturales mundiales, impulsadas por la dinámica de los mercados, revolución tecnológica, redes internacionales productivas, sociedad de la información y el conocimiento y movilidad global de los factores productivos" (Moreno, 2001, p. 109), ha originado la recodificación y apropiación de nuevos lenguajes; una serie de cambios en la cultura visual que da cuenta de las formas de transitar en un tiempo. En esta dinámica, la experiencia de diversas prácticas comunicativas -en este caso, de las artes visuales- ha retratado nuevas prácticas mediante un repertorio de textos multimodales y un lenguaje simbólico que facilita la comprensión de otros espacios juveniles orientados a la construcción de sujeto y a la construcción de otros modos de comunicación en la escuela. De acuerdo con Freedman (2006),
El cambio en la educación artística, como cualquier otro cambio, debe considerarse en relación con una trayectoria histórica amplia. Incluso cuando el tiempo parece corto, los presupuestos y actividades que forman parte del cambio son condiciones del tiempo y del lugar tanto dentro como fuera del campo profesional (p. 35).

Esta importante consideración histórica exige comprender la práctica de la educación artística -artes visuales- en medio de las condiciones culturales, las cuales revelan ciertas características propias de cada contexto sociocultural: "La gama de formas visuales solo puede comprenderse en relación con sus contextos de creación y contemplación. Al mismo tiempo, formas de cultura visual dan forma a estos contextos" (Freedman, 2006, p. 47).

De la revisión de los trabajos académicos de referencia más citados, las investigaciones de Mirzoeff (2003), Freedman (2006), Mejía (2011), Olaya (2009) y Hernández (2010), han introducido estudios de la cultura visual, un concepto que nace en épocas de superproducción en las democracias posindustriales avanzadas y que en el contexto de la educación artística implica, según las investigaciones en educación artística estudiadas por Marín (2011, p. 274), el conjunto de los acontecimientos visuales presentes en la vida cotidiana de los seres humanos, y que se pueden clasificar en:

1. Diversos dispositivos tecnológicos y de comunicación (televisión, ordenador, teléfono móvil, consola de juegos, industria editorial).

2. Locaciones culturales (museos, salas de cine, centros comerciales, parques de atracciones).

3. Otras actuaciones (diseño de muebles, de moda y de interiores, de electrodomésticos, de juguetes, la publicidad, el manga, los tatuajes).

4. Las bellas artes (el dibujo, la pintura, la escultura).

Este es un escenario posmoderno en el que la cultura visual se interesa por: 
[...] los conocimientos visuales en los que el consumidor busca la información, el significado o el placer conectados con la tecnología visual. Entendiendo por tecnología visual cualquier forma de aparato diseñado ya sea para ser observado o para aumentar la visión natural, desde la pintura al óleo, hasta la televisión e internet. (Mirzoeff, 2003, p. 19).

Además de la tendencia de entender la cultura visual en sus artefactos visuales (los objetos), presente en sus diversas manifestaciones y usos simultáneos, es imprescindible comprenderla en sus formas culturales -ideas, creencias y prácticas-, ya que no se puede reducir la experiencia visual del sujeto solamente al consumismo y a la información mediante el carácter perceptivo porque se estaría separando de las cuestiones relacionadas con la construcción subjetiva. Esto significa que la cultura visual demanda, además de la vista, otros sentidos y modos de significación como el auditivo, el gestual, el lenguaje.

Reconocida en sí misma, la cultura visual interdisciplinar y plurimodal (Freedman, 2006, p. 26) se convierte casi en un aspecto indispensable de nuestro pensamiento, sobre todo lo que nos rodea, por constituir una parte destacada de la experiencia humana. En este sentido, para Hernández (2005):

La cultura visual no se refiere solo a una serie de objetos, sino a un campo de estudio que ha ido emergiendo desde la confluencia de diferentes disciplinas, en particular desde la Sociología, la Semiótica, los Estudios culturales y feministas y la Historia cultural, y que dibuja diferentes perspectivas teóricas y metodológicas. Este campo puede pensarse como formado por dos elementos próximos: las formas culturales vinculadas a la mirada y que denominamos como prácticas "visualidad"; y el estudio de un amplio espectro de artefactos visuales que van más allá de los recogidos y presentados en las instituciones del arte (pp. 12-13).

En cuanto a las formas culturales vinculadas a la mirada, evidentemente la velocidad de los cambios, las tecnologías de la información y los medios de comunicación no solo difunden información y determinan interpretaciones precisas de los hechos como única verdad, sino que definen cierto tipo de valores de comportamiento "homogeneizando paulatinamente las estructuras psicosociales valóricas, perceptivas, motivacionales y actitudinales, e incluso, utilizando y modificando en grado desconocido los sustratos instintuales de los seres humanos" (Cooper, 2007, p. 26) con la intención de fabricar ciertos estereotipos y estructuras sociales bajo imágenes impuestas como sistemas de creencias. Esta pretensión de captar la realidad y reproducirla se convierte en la mejor fórmula para simular el mundo. Según Baudrillard (1978), "la única arma absoluta del poder consiste en impregnarlo todo de referentes, en salvar lo real, en persuadirnos de la realidad de lo social, de la gravedad de la economía y de las finalidades de la producción" (p. 47).

En medio de la vivencia de esta ideología dominante, la experiencia estética, además de ser comprendida en los saberes técnicos fundamentales de las artes plásticas y visuales, debe ser parte de un desarrollo educativo en medio de diferentes disciplinas, que supone a la persona como principal protagonista de su proceso de autoconstitución. En ese sentido, en el estudio de la cultura visual es importante prestar atención a la intersección de raza, clase social, clase social, sexo y género para poder elucidar y observar operaciones y formas de visualización y posturas discursivas más complejas (Hernández, 2005, p. 11).

Esta apreciación resulta ser una vía para que la escuela, más allá de hacer un uso técnico de las nuevas tecnologías de la información y la comunicación con su variedad de dispositivos (cámaras digitales, celulares, editores de audio y video, consolas, ordenadores, salas de cine) se integren con los medios de expresión tradicional (dibujo, pintura, diseño) y se comprendan en sus componentes de expresión humana y cultural. Es decir, además de acceder a una oferta ilimitada de herramientas artísticas en distintos tiempos históricos, la escuela 
debe garantizar mediante las artes plásticas y visuales un encuentro con la visualidad.

En este contexto, la función de los docentes ya no consiste solo en facilitar el desarrollo de habilidades técnicas relacionadas con las artes visuales, la música, la danza, el cine u otros lenguajes, sino también en proporcionar un espacio en el que los estudiantes puedan construir significados a partir del conjunto de la información visual, sonora, textual, audiovisual y multimedia a la que diariamente tienen acceso, y crear, publicar, difundir y compartir sus propias producciones. (Giráldez y Pimentel, 2011, p. 127).

En consecuencia, la educación artística debe desplegar con mayor compromiso el mejoramiento y desarrollo de prácticas pedagógicas dirigidas a aprendizajes basados en lenguajes de expresión visual que logren, en la integración entre medios de comunicación visual digital y los de expresión tradicional, "incluirse las imágenes y objetos que más influyen en los alumnos de hoy en día con aquellos que influyeron en las élites del pasado" (Freedman, 2006, p. 12), para desplegar las facultades visuales y simbólicas de los jóvenes y gestar transformaciones en el modo de percibir y comprender el mundo. "Los individuos que quieren participar de un modo significativo en la percepción y creación artística tienen que aprender a descodificar, a leer, [...] de qué modo manipular, de qué modo 'escribir con' las diversas formas simbólicas presentes en su cultura" (Gardner, 1990, p. 30). En esta medida, en el uso y la selección de las imágenes se deben favorecer las relacionadas con los conocimientos previos, integrarlas con otras, para dar la posibilidad de la producción de nuevas imágenes, otras interpretaciones y nuevos significados.

El desarrollo asertivo de las artes plásticas y visuales en la escuela, pensando más en la experiencia estética y desde diversas estrategias pedagógicas -culturales y escolares- y acciones concretas, se puede convertir en una relación constituyente de subjetividades diversas y miradas alternativas más consecuentes por parte de los jóvenes.

El arte, entendido desde una dimensión pedagógica, se convierte en una actividad de desarrollo subjetivo del conocimiento y las potencialidades humanas; esta subjetivación es la forma en que el individuo asume el conocimiento como propio, que lo hace ser reflexivo y le permite actuar sobre sus estados físicos, mentales y espirituales. [...] En pocas palabras se trataría del modo en que un individuo actúa sobre sí mismo. (Mora y Osses, 2012, p. 234).

La autocomprensión consciente de cada sujeto, ¿de quién y cómo es?, reconocida por Foucault (1991) como subjetividad, se convierte casi en uno de los aspectos más significativos en este proceso, pues al estar inmersos en una sociedad de consumo audiovisual, informativo y estético que imponen normas precisas de conducta y prácticas sociales, es pertinente educar para una valoración responsable de la imagen en su producción, reproducción y comercialización; es decir, formar individuos conscientes de su propia configuración como sujeto tanto en el desarrollo intelectual, como emocional.

Este abanico de posibilidades técnicas, culturales y subjetivas, que surgen de las dinámicas que se generan por la velocidad de los cambios y las fuertes motivaciones económicas, ha logrado afectar el contexto educativo en lo relacionado con el protagonismo que ha cobrado la cultura visual, y hoy exige una revisión rigurosa en los encuentros que se producen entre la escuela, la producción estética, las artes plásticas y visuales y la imagen, en cuanto a las formas como el joven se constituye en sujeto, una construcción vinculada con la cultura.

Ahora bien, en el proceso de confrontar esta realidad, desde el aporte de distintos autores que han venido construyendo el campo de las artes visuales y desde la propia experiencia de trabajo con la imagen en la escuela, a continuación 
se describen algunas pistas que surgen entre la cultura visual y su perspectiva educacional, para llegar a la comprensión de otras estrategias de acción que se deben considerar en el uso responsable de la imagen en la escuela. Dichas pistas serán comprendidas en este artículo como consideraciones preliminares para reflexionar, desde una mirada epistemológica, sobre la importancia que cobra la imagen en las artes visuales y la forma como posiblemente esta puede ser orientada a la configuración del sujeto joven.

\section{Sortear la tendencia a la transmisión de imágenes como reflejo transparente de realidades sugeridas}

Esta primera consideración tiene que ver con evitar la tendencia a ciertas habilidades prácticas dirigidas al acercamiento a una especificidad técnica de elementos formales mediante la reproducción de imágenes. En esta consideración se da apertura a la relación entre lo educativo y lo visual, mediada por dos imaginarios presentes en las prácticas pedagógicas: el primero tiene que ver con que la información escolar generalmente ha estado estructurada bajo ciertos modelos tradicionales que consideran la imagen "como una forma de representación inferior y menos legítima que la escritura. En segundo lugar [...], valorar la transmisión de la imagen como un reflejo transparente de realidades simples, una ilustración casi redundante de argumentos reflexivos vinculados a otras formas de expresión" (Dussel y Gutiérrez, 2006, p. 12).

En el escenario de no ver la imagen desde su contenido -vínculos, narrativas y discursos- "la escuela buscará controlar la imagen, ya sea subordinándola al oficio de mera ilustración del texto escrito o acompañándola de un letrero que le indique al alumno lo que dice la imagen" (Barbero, 1996, p. 4). En este sentido, es importante replantear en la escuela la concepción de forma, como el aspecto más relevante respecto al conjunto de relaciones inmersas en las visualidades, para no desdibujar la realidad ni negarle al sujeto la posibilidad de estar en el mundo del acontecimiento, ya que ha habido cierto temor en lo que tiene que ver con la imagen y la desconfianza de la escuela hacia esta (Debray, 1992).

Se busca entonces no contradecir los tiempos juveniles; en cambio, sí se insiste en crear la estructura del tiempo no lineal, no unidimensional, como único tiempo de la institución (Skliar, 2013, p. 136), para así responder a la complejidad de lo que el joven está viendo, sintiendo y siendo, sin interrumpir sus tiempos y lenguajes en lo que respecta a las tecnologías de la imagen. En esta medida, es importante comprender en la escuela, la cultura visual en un escenario nuevo y cambiante en relación con la realidad, "precisamente por centrarse en lo visual como un lugar en el que se crean y discuten los significados" (Mirzoeff, 2003, p. 24), en el que el joven participa de manera directa de sus propias configuraciones mediante el análisis y la construcción de diversas obras como las instalaciones, las fotografías, los vídeos, las historietas, las novelas gráficas, las representaciones gráficas, entre otras expresiones.

\section{Ir más allá de la interpretación de las imágenes en términos de lo negativo/positivo}

Esta segunda consideración, derivada de la primera, está relacionada con las formas interpretativas de las imágenes. La presencia de las imágenes inmersas en el contexto de la cultura visual presentada bajo ciertos tipos de intención (informativa, artística, científica, publicitaria), más que exigir contemplarlas en términos de lo negativo/positivo, se podrían encauzar a otras posibilidades relacionadas con formas variadas de ver el mundo y estar en él. No basta entonces con entender la imagen como una representación exacta o inexacta, sino en su posibilidad de posproducción educativa (transformar y construir en nuevos relatos), es decir, comprenderla en una narrativa social que involucra a los sujetos participantes en dicha visualidad. En esta 
medida se sugiere relacionar las imágenes con un contexto previo, y con otras imágenes, con la intención de proponer nuevas imágenes con nuevos significados. Para Freedman (2006), "el propósito del estudio es desarrollar un acontecimiento más profundo, más rico y más complejo, que a menudo crea conflictos de opinión en vez de soluciones" (p. 39).

La comprensión del modo como pueden asociarse, representar y "discutir esas imágenes y objetos dentro del centro escolar proporciona un foro para los alumnos que no tienen esas conversaciones fuera de este entorno" (Freedman, 2006, p. 13), lo cual genera, además, un reto complejo para la escuela relacionado con la forma de enseñar a mirar con relación a la condición sociocultural del observador. Este método de enseñanza constituye un desafío tanto para docentes como para estudiantes por provocar otras posibilidades de comprender el mundo, viajar por él, cruzar las fronteras culturales y reconstruirse como sujetos a partir de diversas influencias visuales. Bajo esta dirección, "los educadores del arte deben ser siempre conscientes de que están representando una representación, interpretando una interpretación" (p. 29).

Hablar entonces de ir más allá de la interpretación de las imágenes en términos de lo negativo/positivo implica generar en clase aprendizajes interpretativos mediante reflexiones que le apuesten a un amplio alcance en el tiempo y en el espacio, para que la interpretación de los alumnos no dependa de cómo se presenta en una imagen. Es un modo de enseñar que la comprensión de la cultura visual se puede estudiar y ver de otras maneras, incluyendo el modo personal. "La cultura visual aleja nuestra atención de los escenarios de observación estructurados y formales, como el cine y los museos, y la centra en la experiencia visual de la vida cotidiana" (Mirzoeff, 2003, p. 25).

\section{Considerar en la escuela la importancia de las artes plásticas y visuales en la construcción de sujeto}

La tercera consideración enmarcada en la configuración de subjetividades asume que "los modos de representación a través de la esfera de la cultura visual dan forma al pensamiento de las personas" (Freedman, 2006, p. 40), ya que las imágenes producen y median la experiencia de los sujetos mediante las representaciones y construcciones de significados de la vida cotidiana. Al comprender la educación en un proceso de cambio, el aprendizaje que se manifiesta de dicha transformación modifica el yo subjetivo. En esta medida, la cultura visual en la escuela, en lo que respecta a la observación y creación, permite que "los efectos de las imágenes den forma al concepto que el individuo tiene de sí mismo. El individuo se apropia de características de las representaciones visuales, y las adopta como representaciones de sí mismo" (Freedman, 2006, p. 27). Así, las formas de ser y estar de cada sujeto pueden ser tocadas y afectadas por las imágenes, sin ser estas directamente compatibles consigo mismo.

Ahora bien, algunos teóricos posmodernos coinciden en que la imagen, en medio de sus desarrollos tecnológicos y formas avanzadas del capitalismo, ha venido afectando de manera negativa las formas de construcción de sujeto; sin embargo, otros la han considerado en sus diversas manifestaciones como una posibilidad de ver y entender el mundo. Desde la concepción de comprender el proceso de configuración subjetiva vinculado con las relaciones interpersonales y las relaciones con los contextos tanto inmediatos COmo lejanos, la misma subjetividad de los jóvenes reclama un espacio (ámbito de libre desarrollo) donde pueda además de comprender, expresar lo humano sin ser limitado o encasillado en ciertos parámetros sobre el uso o la selección de la información visual. 
Esta lucha de humanización de la escuela se logra con orientaciones claras acerca de los modos de usar, seleccionar y producir imágenes relacionadas con la búsqueda de la propia construcción y transformación de sí mismo para lograr cierto grado de autosatisfacción: "Desde este punto de vista educativo, es crítico comprender la importancia de la representación porque podemos ayudar a dirigir la construcción del conocimiento de formas que enriquezcan las experiencias de los alumnos con el arte" (Freedman, 2006, p. 40). En este sentido, las artes visuales dentro de la educación artística deberían estar encauzadas al desarrollo integral del sujeto, "vinculando los componentes cognitivos y subjetivos, ya que, para lograr aprendizajes significativos, el estudiante debe tener la capacidad de subjetivar los contenidos, hacerlos suyos; apropiarse del conocimiento es un acto subjetivo" (Mora y Osses, 2012, p. 326).

Las tres apreciaciones esbozadas permiten tener un primer acercamiento a la imagen como elemento visual que le otorga significado y sentido al mundo mediante la comprensión de aspectos indispensables en su uso y producción, como: las zonas de interrogación que posibilitan llegar a una imagen; las situaciones sociales, culturales y políticas que facilitan el abordaje de cómo se tocan y afectan las palabras y las imágenes; las sensaciones y pensamientos que despierta, y el plus de las imágenes en la producción.

Comprendida entonces la imagen en el campo de la cultura visual como elemento fundamental, y en la perspectiva de la educación de las artes plásticas y visuales más allá de su representación compositiva de signos y símbolos que registra el significado de realidades sugeridas, se reconoce como narrativa que se expande en una red compleja y de sentidos inscritos en un marco social, donde creadores y receptores se hacen partícipes. En esta dirección, se presenta la imagen a través de dos rasgos distintivos: en su actividad comunicativa, la imagen materializa la experiencia humana en el tiempo y el espacio, y en su "expresión, la imagen es lenguaje joven" (Bachelard, 2000, p. 11).

\section{En su actividad comunicativa, la imagen materializa la experiencia humana en el espacio-tiempo}

Desde el punto de vista del proceso comunicativo como fenómeno inscrito en la producción cultural que involucra sujetos, grupos, saberes y lenguajes (icónicos, verbales y corporales), la imagen convertida hoy en uno de los lenguajes más disponibles y usados cobra un lugar significativo en la construcción de mundo individual y social, porque "es una recreación mental que nos permite imaginar, y de ese modo dar curso a nuestras propias vidas [...]. La imagen, en tanto producción humana, hace suyo lo profundo, lo lejano y extenso para acercarlo a lo inmediato, cercano y específico" (Dussel y Gutiérrez, 2006, p. 12).

La mirada de la imagen como idioma visual no solo hace referencia al arte, la fotografía y el cine, sino, desde hace ya varias décadas, se ha configurado en una relación constitutiva con el universo visual acumulado en la tecnología de la información y la comunicación con la capacidad de producir y reproducir múltiples subjetividades en ambientes distintos de espacio-tiempo. Así lo señaló de manera anticipada Benjamin (2003):

El nuevo arte crea una demanda que se adelanta al tiempo de su satisfacción posible; ejercita a las masas en el uso democrático 'del sistema de aparatos' -el nuevo medio de producción-y las prepara así para su función recobrada de sujetos de su propia vida social y de su historia (p. 23).

Desde esta aproximación, el estudio de la imagen puede entenderse en cuanto producto cultural, como la presencia del tiempo (Deleuze, 2007), lo que permite comprender que el uso y significado de la imagen varían de época en época y de sociedad en sociedad, consolidando prácticas sociales particulares.

Los usos, las variaciones y las relaciones en la materialidad de la imagen los señala con precisión Debray (1992): "[...] la imagen que no soporta la 
misma práctica no puede llevar el mismo nombre" (p. 176). En ese sentido, con la intención, no de construir una historia de la imagen, sino de evidenciar los elementos significativos en distintos momentos, el autor explica la trayectoria de las imágenes a través de tres conceptos clave con temporalidad y pensamiento propio: la logosfera, la grafosfera y la videoesfera. La logosfera, extendida desde la invención de la escritura hasta la de la imprenta, comprende la era de los ídolos -asegura la tradición de lo mágico a lo religioso-, por eso la imagen es concebida como sobrenatural. Es un tipo de imagen realizada por artesanos, y de manera anónima, de ahí que no es una cuestión de estética sino de creencias. La grafosfera, comprendida desde la imprenta hasta la televisión a color, es reconocida como la era del arte -asegura la transición de lo divino a lo humano o lo teológico a lo histórico-, donde el artista se reafirma como tal en el reconocimiento de su propia obra. La videoesfera, que se inicia con el video, pasa por la imagen digital y el mundo virtual, representa la era de lo visual -de la persona puntual en el contexto global-. En esta etapa la imagen virtual es solo eso, imagen visionada; es más un ícono que reproduce y comercializa por estar inmersa en una relación económica, por eso surge a través de los medios de comunicación de masas. Este movimiento histórico de la imagen que combina la lenta y acelerada temporalidad, se puede concretar con apreciaciones como las de Debray (1992):

El ídolo es la imagen de un tiempo inmóvil, síncope de eternidad, corte vertical en el infinito inmovilizado de lo divino. El arte es lento, pero muestra ya figuras en movimiento. Nuestro visual está en rotación constante, ritmo puro, obsesionado con la velocidad [...]. El ídolo es autóctono, pesadamente vernacular, enraizado en un suelo étnico. El arte es occidental, campesino pero circulante y dotado para el viaje (Durero a Italia, Leonardo a Francia, etc.). Lo visual es mundial (mundovisión), concebido desde la fabricación para una difusión planetaria (p. 177).
En el sentido de que esta apreciación invita a pensar que como sujetos sociales, llevamos los tres tipos de imágenes en nuestra memoria histórica, la palabra imagen reconocida como práctica, socialización y comunicación que en palabras de Deleuze (2007) no se confunde con el espacio recorrido, sino con el acto de transitar, permite conocer historias movilizadoras por pertenecer al orden de la apariencia y la imaginación. En este sentido, "el índice histórico de las imágenes no solo dice a qué tiempo determinado pertenecen, dice sobre todo que solo en un tiempo determinado alcanzan legibilidad" (Benjamin, 2003, p. 465).

La imagen, entonces, comprendida como una construcción cultural, por su agudeza, va en correspondencia con la realidad, con la imaginación que se tiene de la sociedad y la narración de la propia vida. Así, "las imágenes habría que considerarlas como un objeto y como condición de nuestra existencia, como artefactos que nos atraviesan como personas y como ciudadanos, y que atraviesan nuestras formas de saber" (Dussel, 2005, p. 163), pensar, estar y percibir el mundo. En esta significación social, "en la práctica la imagen está sujeta, restringida en esta producción de sentido o si no pierde todo el sentido, se vuelve ilegible" (Fischman, 2006, p. 240), porque las imágenes más que una representación de algo, son un lenguaje que, en la producción de sentido, dan forma a la dimensión social pues su uso como práctica es entendida en una red comunicacional que constituye la experiencia humana.

Esta apreciación es confirmada por los mismos jóvenes en la escuela cuando usan y crean mundos enteros derivados de la cultura visual y codifican sus nuevas producciones y comportamientos con imágenes representativas y redundantes. "El impacto de las imágenes plantea una gran variedad de cuestiones sociopolíticas y económicas que, a su vez, influyen en las identidades de los alumnos, en las nociones de ciudadanía, las creencias sobre la democracia, etc." (Freedman, 2006, pp. 232-233). Esta consideración sugiere que el sujeto, al estar expuesto a diversos repertorios visuales 
inmersos en una época con ciertas modalidades culturales, produce experiencias particulares que terminan por configurar subjetividades diversas y cambiantes en espacio/tiempo.

\section{En su expresión, la imagen es lenguaje joven}

En las últimas décadas, como lo anuncia Neil (1991), "la nueva imagen, con la fotografía al frente, no funcionaba meramente como un suplemento del lenguaje, sino que intentaba reemplazarlo" (p. 79), debido a que este crítico cultural sitúa el mundo de la imagen en el mismo sujeto, en la producción del conocimiento, y en el espacio y el tiempo de la diversión y el espectáculo dado en el mundo virtual de los mass media.

Así, la información visual convertida hoy en espectáculo mercantilista gracias a los nuevos dispositivos tecnológicos y sus potentes aplicaciones para el procesamiento de imágenes y la conectividad constante, ha generado ciertas prácticas sociales que cambiaron el objeto de la imagen, como es la interferencia entre la percepción y la expresión. En medio de las prácticas que nacen en la incorporación del sujeto en este ecosistema comunicacional del atractivo visual, se puede considerar que al estar la imagen inmersa en el lenguaje estratégico de lo digital -conectividad, simultaneidad, visualidad e hipertextualidad-, pasa hoy por la crisis de representación (Barbero, 1997, p. 9) y la muerte de la realidad en la era de los mass media, de lo virtual y de las redes. (Baudrillard, 1998, p. 10).

La imagen como lenguaje joven, "no solo por su omnipresencia sino por su fuerte poder persuasivo: se asocia a prácticas culturales -forma parte de lo que está pasando-, se vincula a las experiencias de placer -se presenta narrativamente atractiva- y se relaciona con formas de socialización -los sujetos se sienten parte de un grupo con el que se identifican-" (Hernández, 2001, p. 1). En este sentido, la imagen visual, en sus diversos modos de movilidad, afecta las visiones de mundo porque con sus nuevos significados asociados a las redes en que está inmersa, esta "se vuelve código y se inserta en otros códigos más amplios adaptándose a sus propias lógicas. La imagen se vuelve un interfaz, una conexión y, de alguna forma, un lenguaje, con una estética socio técnica" (Gómez, 2012, p. 406).

Por otro lado, la imagen incorporada en los modernos desarrollos de la cultura visual, en la temporalidad de lo novedoso, también es entendida en una diversidad de formas comunicativas, donde se pone en movimiento toda una actividad lingüística (Bachelard, 2000, p. 14) al producir cambios en las características de los textos. El papel protagónico que toma la imagen en los textos multimodales configura la estructura, no solo de los medios masivos de comunicación, sino también de los lenguajes tradicionales como libros, revistas y galerías, los cuales exigen leerse en diálogo con los otros modos semióticos: "Es decir, los productores de textos hacen un uso cada vez mayor y más deliberado de una gama de modos de representación y comunicación que coexisten dentro de un texto dado" (Krees, Leite-García y Van Leeuwen, 2000, p. 374). Aunque la multimodalidad como una serie de modos de comunicación siempre ha existido, en la actualidad las altas posibilidades de significación de los diversos modos -visual, verbal, sonoro- requieren de una seria reflexión para comprender la conjunción de estos y sus respectivas contribuciones a la percepción de los sujetos.

Ahora bien, la inquietud por la imagen como lenguaje joven en medio de su acelerada evolución, también radica en las formas de significación como actividad social; es decir, cómo los usos ofrecidos en los modos visuales de los textos multimodales son descifrados por el lector a su modo. En este panorama, "las ilustraciones se convierten en retos intelectuales, trampas a la inteligencia [...] el ilustrador que utiliza el ingenio busca la complicidad del espectador reclamándole la capacidad de relacionar la experiencia vivida con la experiencia propuesta por la imagen" (Durán, 2009, p. 101). Así, la imagen, a la vez que se usa en función de 
una necesidad, se descifra en un estilo de vida propio, porque las imágenes no solo se ven, también se imaginan, se construyen en la mente a partir de la palabra y de las posibilidades de significación.

Estas formas de interpretar el contenido del lenguaje visual en sus múltiples modos de significación nos lleva a comprender que cada vez la imagen alcanzará mayor grado de legitimidad, aprobación y reconocimiento, por eso la importancia de reconocer que "[...] mirar con atención las imágenes, nos lleva, entre otros destinos, a pensar cómo nos ofrecen versiones concretas de categorías sociales como género, clase, raza, sexualidad, capacidades, entre otras" (Hernández, 2005, p. 26).

Desde este lugar de enuncación comprendido en medio de los dos rasgos distintivos propuestos, se concibe la imagen como componente de la subjetividad, como contexto que evoca a un mundo entero, a un conjunto de correlaciones que da sentido a las cosas. Es un lenguaje enmarcado en nuevas formas que producen ciertos esquemas de representación social o estereotipos que terminan por direccionar prácticas sociales y propiciar nuevas formas de sujeto. Atendiendo a esta consideración, vale admitir que no existen métodos ni estrategias para enseñar a ver; se ve desde cada percepción, cada mirada que dice quién y cómo se ve, porque se ve desde adentro, desde la experiencia y emocionalidad propia. Así, la imagen en sus nuevos modos de sensibilización, enseña a narrar y a narrarse, a mirar y a mirarse, a comprender el mundo propio y el del otro a partir de otras formas de relación, pero sobre todo a partir de la experiencia social propia.

En esta redefinición de la imagen construida desde el campo de la cultura visual en la perspectiva de la educación, se hace importante reconocer que a pesar del abanico de posibilidades que ofrece la imagen en las artes plásticas y visuales en la escuela, al igual que las artes escénicas, las artes musicales y el arte danzario, se han visto expuestas a un desdibujamiento e invisibilización por agrupar en un todo la especificidad de cada disciplina; tradición dada en la misma problemática que ha tenido que confrontar la cultura escolar en su afán de incluir en su currículo un plan de estudios y metodologías estandarizadas. En este sentido, el recorrido histórico de la educación artística concretamente en la artes visuales ha dejado ver que el currículo se ha interesado más en el concepto del objeto artístico (producción final, historia del arte, crítica y estética) que en otro tipo de formas visuales (grafitis, performances, dibujos animados, videoarte), convirtiéndose esta mirada en un enfoque académico del currículo, en oposición a un enfoque humanista (McNeil, 1975).

\section{A MANERA DE CONCLUSIÓN}

Desde esta mirada general al campo de la cultura visual en la perspectiva de la educación de las artes plásticas y visuales, y de la sensación de que la cultura visual en la comunicación propicia el acercamiento de la escuela a la sociedad, el diálogo entre medios de comunicación/saber, la relación imagen/sentir de los jóvenes, conviene a la educación artística específicamente a lo que respecta a la disciplina en cuestión una búsqueda de nuevos horizontes en las prácticas pedagógicas. Es un replanteamiento y autosignificación desde los mismos docentes, donde más allá de dar cumplimiento a programas académicos ya establecidos, se interpele la escuela y se plantee desde la relación cultura visual/artes visuales nuevas formas de significar la imagen como hecho comprensible, desde los sentidos que cada individuo le otorga a su experiencia visual en su autoconstrucción de sujeto.

Esta relación entre las formas de visualidad contemporánea donde se comprende la dimensión social de la mirada con la cultura visual, en cuanto formas y modos culturales, demanda un diálogo necesario entre la pedagogía cultural -papel que desempeña el universo cultural en la configuración de subjetividades- y la pedagogía escolar -lo que se supone que la escuela pretende transmitir en su propuesta educativa-. En consecuencia, la 
educación de las artes plásticas y visuales comprendida como un campo que posibilita la producción de nuevas miradas e interpretaciones, debe generar espacios donde el sujeto reconozca en la imagen los acontecimientos narrativos que promueven la experiencia estética, y más aún cuando estas, a partir de ciertas formas de simbolización, son apreciadas como formas legítimas de arte. Es una tarea que debe partir de esbozar un marco conceptual donde se integre la actividad estética de las artes visuales con la construcción subjetiva de los jóvenes.

Desde este panorama, se propone a la escuela como un escenario donde se busque comprender que "en el truco de lo visual no se trata nunca de confundirse con lo real, sino de producir un simulacro, con plena conciencia del juego y del artificio" (Baudrillard, 1978, p. 30), para objetar la imposición de la imagen como mera representación de realidades insinuadas bajo ciertos simulacros -conjunto de signos- que operan como superposición de lo real, por una interpretación crítica de los hechos bajo posibilidades interpretativas diversas. Este proceso solo se logra mediante prácticas pedagógicas enmarcadas en la construcción de sujeto, donde se reconozca al otro como individuo de subjetividades diferenciales.

Revelar el sentido social de la nueva cultura visual no es fácil, pero la escuela como escenario educativo se convierte en el puente de este pretensioso interés. Desde esta perspectiva, y desde la concepción de que "el objeto de los estudios de cultura visual sería la visualidad humana" (Hernández, 2005, p. 28), se sugiere empezar por comprender que la educación en artes plásticas y visuales no se puede centrar en un objeto artístico que responde más al mantenimiento del conocimiento tradicional (cualidades formales y técnicas) porque se estaría reduciendo a una única línea de desarrollo estilístico occidental. "El currículo tendrá que prestar una mayor atención al impacto de la formas visuales de expresión más allá de los límites tradicionales de la enseñanza y el aprendizaje, incluyendo los límites de las culturas, las disciplinas y las formas artísticas" (Freedman, 2006, p. 47). En el sentido entonces de romper los límites del objeto, el currículo debe centrar la atención en las interpretaciones y conexiones con la cultura visual; ejercicio que lleva a cierto grado de interdisciplinariedad por la gama de contenidos que ofrece este tipo de cultura.

Desde esta perspectiva, la educación artística se convierte en un campo para "ayudar a los alumnos a conocer las artes visuales en su complejidad, sus relaciones y sus independencias, sus ideas contradictorias y sus objetos aceptados, y sus conexiones con el pensamiento social y con otras prácticas profesionales" (Freedman, 2006, p. 46). En esta consideración de las artes visuales de nuevas y muchas formas, una de las responsabilidades de la educación artística es concientizar a los alumnos acerca de su comprensión del papel central del arte en la condición humana y del poder de las imágenes y el uso responsable de dicho poder en cuanto su contemplación y producción, con la posibilidad de despertar la provocación hacia la reflexión y construcción de ideas relacionadas con la cultura visual, sus significados y su desbordante crecimiento.

\section{RECONOCIMIENTOS}

Este artículo de reflexión forma parte del proyecto de tesis doctoral "La imagen en la cultura visual y sus implicaciones en los procesos de subjetividad de los jóvenes. Cuestiones para pensar y transformar las prácticas pedagógicas en las artes visuales", efectuado en el Doctorado Interinstitucional en Educación, sede Universidad Distrital Francisco José de Caldas, Bogotá (Colombia), y dirigido por la doctora Sandra Soler Castillo a quien le reconozco su trabajo riguroso, sensible y provocador hacia otras formas más humanas de comprender las prácticas educativas.

También quiero ofrecer un reconocimiento a la Secretaría de Educación Distrital en el marco del Plan de Desarrollo de la Ciudad, del Plan Sectorial 
de Educación Distrital y Plan Territorial de Formación Docente 2008-2012 por las nuevas políticas de formación y actualización del Equipo Docente mediante el Fondo de Formación Avanzada para Docentes (FOFAD) materializadas en un incentivo educativo condonable por contraprestación de servicios, del cual estoy siendo beneficiaria como estudiante de doctorado.

\section{REFERENCIAS}

Bachelard, G. (2000). La poética del espacio. Bogotá: Fondo de Cultura Económica.

Barbero, M. (1993). La comunicación en las transformaciones del campo cultural. Revista Alteridades, 5, 59-68.

Barbero, M. (1996). Heredando el futuro. Pensar la educación desde la comunicación. Revista Nómadas, $5,1-14$.

Barbero, M. (2003). De los medios a las mediaciones. Comunicación, cultura y hegemonía. Bogotá: Convenio Andrés Bello.

Baudrillard, J. (1978). Cultura y simulacro. Barcelona: Editorial Kairós.

Baudrillard, J. (1998). ¿Por qué no todo ha desaparecido aún? Buenos Aires: Libros del Zorzal.

Benjamin, W. (2003) La obra de arte en la época de su reproductividad técnica. México, D.F: Editorial Itaca.

Cooper D. (2007). Ideología y tribus urbanas. Santiago: LOM Ediciones.

Debray, R. (1992). Vida y muerte de la imagen. Historia de la mirada en Occidente. Barcelona: Paidós.

Deleuze, G. (2007). Empirismo y subjetividad. Barcelona: Gedisa

Durán, T. (2009). Álbumes y otras lecturas. Análisis de los libros infantiles. Barcelona: Octaedro-Asociación de Maestros Rosa Sensat.

Dussel, I. (2005). Educar la mirada: notas sobre los aportes de la mirada a la formación docente. Revista Belo Horizonte, 41, 157-174.

Dussel, I. y Gutiérrez, D. (comp.) (2006). Educar la mirada: políticas y pedagogías de la imagen. Buenos Aires: Manantial, Fundación OSDE.
Fischman, G. (2006). Aprendiendo a sonreír, aprendiendo a ser normal. Reflexiones acerca del uso de fotos escolares como analizadoras en la investigación educativa. En: I. Dussel y D. Gutiérrez, D. (comp.). Educar la mirada. Políticas y pedagogías de la imagen. (pp. 235-254) Buenos Aires: Manantial, Fundación OSDE.

Freedman, K. (2006). Enseñar la cultura visual. Currículum, estética y la vida social del arte. Barcelona: Octaedro.

Foucault, M. (1991). El sujeto y el poder. Bogotá: Carpe Diem Ediciones.

Gardner, H. (1990). Educación artística y desarrollo humano. Barcelona: Paidós Educador.

Giráldez, A. y Pimentel, L. (2011). Artes y tecnologías en la escuela. En: A. Giráldez y L. Pimentel (coord.). Educación artística, cultura y ciudadanía. De la teoría a la práctica (pp. 127-133). Madrid: Organización de Estados Iberoamericanos (OEI). Recuperado de http://www.oei.es/metas2021/LibroEdArt_Delateoria-prov.Pdf

Gómez, E. (2012). La fotografía digital como una estética sociotécnica: el caso de la Iphoneografía. Aisthesis, Revista Chilena de Investigaciones Estéticas, 52, 393-406. Recuperado de: http://www.scielo.cl/ pdf/aisthesis/n52/art20.pdf

Hernández, F. (2001). La necesidad de repensar la educación de las artes visuales y su fundamentación en los estudios de cultura visual. Presentación en el Congreso Iberoamericano de Arte-Educación. Porto, Portugal.

Hernández, F. (2005). ¿De qué hablamos cuando hablamos de cultura visual? Revista Educacao \& Realidade, 2, 9-34. Universidade Federal Do Rio Grande Do Sul.

Hernández, F. (2010). Educación y cultura visual. Barcelona: Editorial Octaedro.

Hernández, F. (2013). Transitar y aprender dentro y fuera de la escuela: la relación de los jóvenes con la cultura visual como espacio de posibilidad y autoría. En: Grupo de Investigación Edarte. Investigar con jóvenes. ¿Qué sabemos de los jóvenes como productores de cultura visual? (pp. 83-92). Pamplona: Pamiela-Edarte (UPNA/NUP). Recuperado de: 
http://edarte.org/wp-content/uploads/2013/03/Investigar_con_jóvenes_Edarte.pd

Krees, G.; Leite-García, R. y Van Leeuwen, T. (2000). Semiótica discursiva. En: T.A. Van Dijk (coord.). El discurso como estructura y proceso (pp. 373-416). Barcelona: Gedisa

Marín, R. (2011). Las investigaciones en educación artística y las metodologías artísticas de investigación en educación: temas, tendencias y miradas. Revista Educacao, Porto Alegre, 34, 271-285. Pontificia Universidade Católica de Rio Grande do Sul.

McNeil, J.D. (1975). Curriculum: A Comprehensive Introduction. Nueva York: Scott Foresman.

Mejía, S. (2011). La educación artística como comprensión crítica de la cultura visual en Fernando Hernández. Pensamiento, palabra y obra, 2(2), 36-43.

Mirzoeff, N. (2003). Una introducción a la cultura visual. Barcelona: Paidós.

Mora, J.M. y Osses, S. (2012). Educación artística para la formación integral: complementariedad entre cultura visual e identidad juvenil.
Estudios Pedagógicos, XXXVIII(2), 321-335. Recuperado de: http://www.redalyc.org/articulo. oa?id=173524998019

Moreno P. (2001). Escenarios para la educación en el contexto de la globalización y la posmodernidad. Revista de la Facultad de Economía-BUAP, 16, 107-122. México: Universidad Autónoma de Puebla.

Neil, P. (1991). Divertirse hasta morir. Barcelona: Ed. de la Tempestad.

Olaya, O.L (2009). Enseñanza de las artes visuales en Colombia. Revista digital DO laboratorio De arte Visuais, 2, 1-6. Centro de Educacao, Universidade Federal de Santa María. Brasil. Recuperado de: $<$ http//cascabel.ufsm.br/revistas/ojs-2.2.2/index. php/revislav/artivle/view/2172/1312>

Saenz, J. (2003). Pedagogía y epistemología. Hacia una pedagogía de la subjetivación. Bogotá: Magisterio.

Skliar, C. (2013). Acerca de los argumentos del cambio educativo. La crisis de la racionalidad pedagógica. Revista Educatio Siglo XXI, 2, 129-146. 